\section{Research Square \\ Preprints are preliminary reports that have not undergone peer review \\ They should not be considered conclusive, used to inform clinical practice, or referenced by the media as validated information.}

\title{
The Effect of Transactional Analysis Training On Emotional Intelligence In Health Professions Students
}

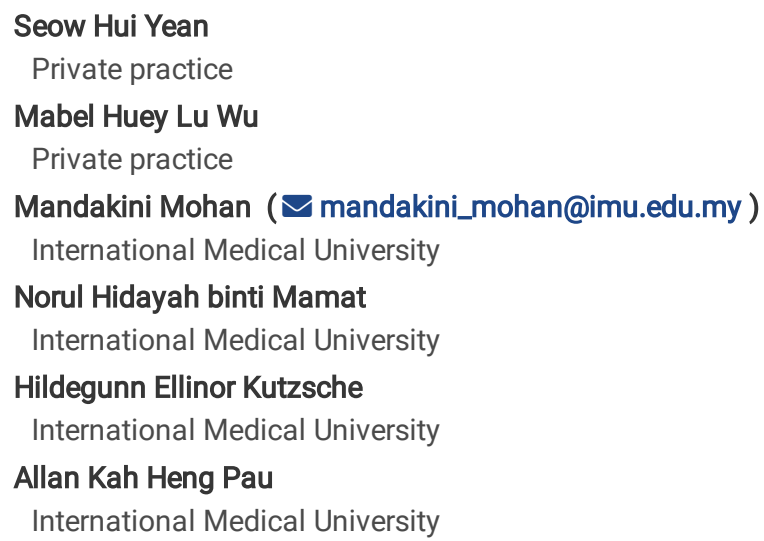

Research Article

Keywords: Emotional Intelligence, Transactional analysis, Health professions

Posted Date: June 2nd, 2021

DOI: https://doi.org/10.21203/rs.3.rs-530526/v1

License: (ㄷ) (i) This work is licensed under a Creative Commons Attribution 4.0 International License. Read Full License 


\section{Abstract}

\section{Background}

We evaluated the effect of psycho-educational training in emotional intelligence (EI) and transactional analysis (TA) (TEITA) on El in health professions undergraduates, post-training and at 1-month follow-up.

\section{Methods}

A total of 34 participants participated in the study where 17 participants were in TEITA group and another 17 were in control group. A quasiexperimental nonrandomised, controlled cohort was conducted, in which participants in TEITA group were introduced to El and TA concepts on a weekly basis for four weeks, at 90 minutes each time, and provided with opportunities for experiential sharing of emotions and coping mechanisms experienced in the previous week. Both TEITA and control groups received weekly El and TA reading materials. All completed the 16-item Wong and Law El Scale at baseline and post-training. Training group also completed the questionnaire at 1-month follow-up. Wilcoxon Signed Ranks and Mann Whitney tests were used to analyse within group and between group changes in El scores.

\section{Results}

Baseline EI scores in TEITA group were lower than control group. On completion of TEITA, El scores in TEITA group increased, and differences were not detected between groups. Within TEITA group, paired increases in all domains were statistically significant, whereas in the control group, paired increase was only detected in the domain addressing regulations of emotion (ROE). Pre to post-training increases in El scores were statically significantly greater in TEITA compared to control groups. At the 1-month follow-up, El were sustained.

\section{Conclusion}

The psycho-educational training based on El and TA is effective in enhancing El in health professions students. Future research should investigate the effect of such training on observable inter-personal and socio-economic behaviours.

\section{Background}

Emotional intelligence (EI) has been termed as a set of abilities for sophisticated information processing about emotions and emotion-relevant stimuli, and using this information as a guide to thinking and behavior (1). El is an important factor that has been related to educationally and socially relevant outcomes and theoretically linked to academic performance $(2,3)$, workplace effectiveness, including doctor-patient relationship and leadership (4-6), and psycho-social well-being $(7,8)$. It has been suggested that personal growth and development, through emotional learning and maturation in emotional intelligence, are central to developing professional competence (9). This led to more research needed to determine whether El can be improved through training and augmenting educational and clinical outcomes (4). The need to develop such training programmes to promote El abilities, such as communication and conflict resolution has been called for (7).

The integration of El training into medical and health professions education is supposed to contribute to teaching of professionalism (10,11) and developing communication skills (12). Interventions involving simulated patients (13), mental health awareness training (14) and leadership training (15) are effective to promote El. An interesting consideration in the development of training to enhance El in communication and interpersonal skills is the incorporation of transactional analysis (TA) training (16), as TA has often been discussed in communication and leadership training for healthcare workers (17). In a recent study, group therapy among drug addicts with TA approach showed significant effects on El expressed by coping capabilities (18).

The socio-psychological theory of TA explains that ego states are parts of our personality, systems of thinking, behaviors and feelings and can be identified as the ego state of the Parent, the Adult and the Child. None of the above ego states ranks over the other, but we need to align the ego states with the situation we are faced by. The Parent ego state reflects parental thoughts and feelings; the Adult ego state relates to thoughts and feelings based on our own experiences, information, personal process and previous experiences; and the Child ego state is based on thoughts and feelings replayed from childhood (19). TA provides a systematic approach that helps understand the link between human needs and behaviors, and the way that individuals, groups and organizations are effective or ineffective in communicating. It has been used to explain the psycho-emotional exploitation that can take place during patient encounters and result in emotional exhaustion of clinicians (20). Similarly its relevance in understanding the challenges that can emerge in the clinical supervision context (21), as well as offering insight into our own behaviours and relationships (19) has been reported. In clinical supervision, TA can be used to enhance the understanding of interpersonal interactions and improve the outcomes of clinical training(22). Training in TA tools has been shown to result in sustainable and measurable improvement in self-awareness (23), a domain that is recognized in the El framework. The basis for TA and the ego-state types in developing communication skills training for medical (24), pharmacy (25) and nursing students (26) has also been recommended.

The literature would appear to suggest that both the TA tool and the El ability have useful applications in interpersonal professional and social encounters. In such encounters, in which a transaction takes place between two or more people, the TA tool may be used to identify the ego states at 
play and the El ability used to assess the emotions that are expressed or suppressed. The application of TA and El may therefore help to effect more constructive communication and teamwork.

In this study, we tested the effect of psycho-educational training in El and TA (TEITA) on changes in El scores between baseline and on completion of TEITA, and at the 1-month follow-up.

\section{Methods}

A quasi-experimental non-randomised controlled cohort study was conducted on health professions undergraduates at one university to compare the baseline, post-training and 1-month follow-up of El scores of participants who completed a four-week psycho-educational training in El and TA (TEITA) and those given reading material on TA and El. Institutional ethics approval was obtained (BDS I1-13(13)-2016).

The TEITA involved four weekly 90-minute sessions designed by members of the research team (PKH, KHE, MNH). The aims of TEITA were to introduce participants to El and TA and support experiential sharing of emotions experienced in the previous week and mechanisms used to cope with those emotions. Each session began with a discussion on various aspects of the El and TA concepts for 45 minutes, followed by 45 minutes of experiential sharing. Each session was facilitated by two psychologists (KHE, MNH) and two research assistants (SHY, WHL). Both the TEITA and control groups received reading materials on TA and El on a weekly basis. The reading material included articles and internet resources. (Fig. 1)

The sampling population were health professions, i.e. medicine, dentistry, pharmacy and psychology, undergraduates at one university. Based on a $95 \%$ confidence level and $80 \%$ power, a sample size of 34 subjects (17 in control and 17 in TEITA groups) was estimated to detect a difference of $50 \%$ in proportion of subjects increasing their El scores between baseline and post-training. This assumed that $10 \%$ of the control participants and $60 \%$ of the TEITA participants would have increased their El scores from baseline to post-training.

Potential participants were approached by email to voluntarily participate in this study. Flyers were placed around the university campus and on the screensaver of university computers. Information given to potential participants included the aim of the research, the time and venue, number of participants required, the benefits of participating in the research, as well as the contact researcher's information. Participants who volunteered and consented in writing to receiving TEITA were assigned to the training group, whereas those not interested in TEITA were assigned to the control group. Participants assigned to the training group were divided into 2 small groups, each receiving the TEITA separately. Participants were assured of confidentiality and written consent was obtained.

The El instrument used was the 16-item self-report Wong and Law El Scale (WLEIS) measured on a 7-point Likert-type scale (27), from $1=$ totally disagree to 7-totally agree. These 16 items are distributed into four domains: self-emotional appraisal (SEA), others' emotional appraisal (OEA), use of emotion (UOE) and regulation of emotion (ROE). The WLEIS has since been widely validated across different contexts (28-30). All participants completed the WLEIS at baseline and on completion of the 4-week TEITA. The training group also completed the WLEIS at the 6-month follow-up.

\section{Data analysis}

The Statistical Package for Social Sciences (SPSS) software for Windows, Version 18.0 was used for statistical analysis. Sample characteristics between the training and control groups were compared using the Chi-square test for distribution by sex, and Mann-Whitney test for differences in age and El scores. Baseline and post-training El scores between training and control groups were compared using the Mann Whitney test. Paired changes in El scores from baseline to completion of TEITA within the training and control groups were tested using the Wilcoxon Signed Ranks test. The primary outcome of changes in El scores from baseline to post-training were compared between the training and control groups. Paired changes in El scores from baseline to 1-month follow-up for the training group were tested for statistical significance using the Wilcoxon Signed Ranks test. Statistical significance was set at $\mathrm{p}=0.05$.

\section{Results}

Of 19 (55.9\%) females enrolled, 14 (73.7\%) volunteered for the TEITA compared to $3(20.0 \%)$ of the $15(44.1 \%)$ males ( $p=0.002)$. The median age (inter-quartile range) of participants in the intervention group was $22(19-23)$ and $22(21-23)$ in the control group $(p=0.156)($ Table 1$)$. 
Table 1

Baseline comparison between intervention and control groups by sex, age and $\mathrm{EI}$

scores

\begin{tabular}{|llll|}
\hline & Intervention $(\mathbf{n}=17)$ & Control $(\mathbf{n}=17)$ & p-value \\
\hline Female $(\mathrm{n}=19,55.9 \%)$ & $14(73.7 \%)$ & $5(26.3 \%)$ & 0.002 \\
\hline Male $(\mathrm{n}=15,44.1 \%)$ & $3(20.0 \%)$ & $12(80.0 \%)$ & \\
\hline Age in years: median (IQR) & $22(19-23)$ & $22(21-23)$ & 0.156 \\
\hline El Total: median (IQR) & $75.0(62.0-81.0)$ & $82.0(77.0-90.0)$ & 0.027 \\
\hline SEA & $19.0(17.5-21.5)$ & $23.0(20.5-24.0)$ & 0.005 \\
\hline OEA & $18.0(13.0-20.0)$ & $20.0(17.5-23.5)$ & 0.049 \\
\hline UOE & $20.0(15.5-22.0)$ & $20.0(17.5-23.0)$ & 0.578 \\
ROE & $17.0(15.0-21.0)$ & $19.0(18.0-22.0)$ & 0.107 \\
\hline
\end{tabular}

At baseline, males scored more highly in SEA (0.045) compared to females, but both groups were similar for EI Total (0.266), OEA (0.689), UOE (0.990) and ROE (0.062) (Table 2). On completion of TEITA, no difference between the two groups was detected. Among the females, statistically significant paired increases in El Total and all domain scores were detected. Similarly, paired increases were detected among males. However, increases in El and all domains scores from baseline to completion of TEITA were not statistically significantly different between the two groups.

Table 2

Comparison of El scores between and within females and males

\begin{tabular}{|c|c|c|c|c|c|c|c|c|c|c|c|}
\hline & \multicolumn{2}{|l|}{ Pre } & \multirow{2}{*}{$\begin{array}{l}\text { Pre-scores } \\
\text { between } \\
\text { groups } \\
{ }^{\text {ap-value }}\end{array}$} & \multicolumn{2}{|l|}{ Post } & \multirow{2}{*}{$\begin{array}{l}\text { Post- } \\
\text { scores } \\
\text { between } \\
\text { groups } \\
\text { ap-value }\end{array}$} & \multirow{2}{*}{$\begin{array}{l}\text { Paired score } \\
\text { changes } \\
\text { within } \\
\text { females } \\
{ }^{\mathrm{b} p \text {-value }}\end{array}$} & \multirow{2}{*}{$\begin{array}{l}\text { Paired score } \\
\text { changes } \\
\text { within males } \\
\\
{ }^{\mathrm{b} p \text {-value }}\end{array}$} & \multicolumn{2}{|l|}{ Post-Pre } & \multirow{2}{*}{$\begin{array}{l}\text { Post-Pre } \\
\text { score } \\
\text { changes } \\
\text { between } \\
\text { groups } \\
\text { ap-value }\end{array}$} \\
\hline & Female & Male & & Female & Male & & & & Female & Male & \\
\hline $\begin{array}{l}\text { El } \\
\text { Total }\end{array}$ & $\begin{array}{l}77.0 \\
(71.0- \\
83.0)\end{array}$ & $\begin{array}{l}81.0 \\
(73.0- \\
92.0)\end{array}$ & 0.266 & $\begin{array}{l}86.0 \\
(81.0- \\
83.0)\end{array}$ & $\begin{array}{l}85.0 \\
(78.0- \\
97.0)\end{array}$ & 0.781 & 0.001 & 0.002 & $\begin{array}{l}9.0 \\
(4.0- \\
19.0)\end{array}$ & $\begin{array}{l}7.0 \\
(1.0- \\
11.0)\end{array}$ & 0.348 \\
\hline SEA & $\begin{array}{l}20.0 \\
(18.0- \\
21.0)\end{array}$ & $\begin{array}{l}24.0 \\
(19.0- \\
24.0)\end{array}$ & 0.045 & $\begin{array}{l}23.0 \\
(22.0- \\
25.0)\end{array}$ & $\begin{array}{l}24.0 \\
(21.0- \\
25.0)\end{array}$ & 0.986 & 0.006 & 0.048 & $\begin{array}{l}3.0 \\
(0.0- \\
7.0)\end{array}$ & $\begin{array}{l}1.0 \\
(0.0- \\
6.6)\end{array}$ & 0.136 \\
\hline OEA & $\begin{array}{l}19.0 \\
(15.0- \\
23.0)\end{array}$ & $\begin{array}{l}18.0 \\
(16.0- \\
21.0)\end{array}$ & 0.689 & $\begin{array}{l}23.0 \\
(19.0- \\
24.0)\end{array}$ & $\begin{array}{l}20.0 \\
(18.0- \\
24.0)\end{array}$ & 0.637 & 0.021 & 0.008 & $\begin{array}{l}1.0 \\
(0.0- \\
6.0)\end{array}$ & $\begin{array}{l}2.0 \\
(0.0- \\
5.0)\end{array}$ & 1.000 \\
\hline UOE & $\begin{array}{l}20.0 \\
(19.0- \\
23.0)\end{array}$ & $\begin{array}{l}20.0 \\
(16.0- \\
23.0)\end{array}$ & 0.930 & $\begin{array}{l}22.0 \\
(20.0- \\
24.0)\end{array}$ & $\begin{array}{l}21.0 \\
(19.0- \\
23.0)\end{array}$ & 0.329 & 0.005 & 0.024 & $\begin{array}{l}3.0 \\
(0.0- \\
5.0)\end{array}$ & $\begin{array}{l}1.0 \\
(0.0- \\
2.0)\end{array}$ & 0.186 \\
\hline ROE & $\begin{array}{l}18.0 \\
(15.0- \\
20.0)\end{array}$ & $\begin{array}{l}22.0 \\
(18.0- \\
24.0)\end{array}$ & 0.062 & $\begin{array}{l}21.0 \\
(18.0- \\
23.0)\end{array}$ & $\begin{array}{l}24.0 \\
(19.0- \\
23.0)\end{array}$ & 0.215 & 0.005 & 0.015 & $\begin{array}{l}2.0 \\
(-1.0- \\
5.0)\end{array}$ & $\begin{array}{l}2.0 \\
(0.0- \\
3.0)\end{array}$ & 0.625 \\
\hline \multicolumn{12}{|c|}{${ }^{\mathrm{a}}$ Mann-Whitney Test for differences between groups } \\
\hline
\end{tabular}

At baseline, the control group scored more highly in El Total (0.027), SEA (0.005), OEA (0.049 and OEA (0.049) (Table 3). Both groups scored similarly in UOE (0.578) and ROE (0.107). However, on completion of TEITA, both groups scored similarly in El Total and all its domains. Within the training group, paired increases in El Total and all domain scores were statistically significant. Within the control group, paired increases in El Total (0.012) and ROE (0.010) were statistically significant. Increases in scores from baseline to completion of TEITA were statically significantly different between the two groups for EI Total (0.002), SEA (0.001), OEA (0.027) and UOE (0.017), but not ROE (0.252). 
Table 3

Comparison of El scores between and within intervention and control groups

\begin{tabular}{|c|c|c|c|c|c|c|c|c|c|c|c|}
\hline & Pre & & $\begin{array}{l}\text { Pre- } \\
\text { scores } \\
\text { between } \\
\text { groups }\end{array}$ & Post & & $\begin{array}{l}\text { Post- } \\
\text { scores } \\
\text { between } \\
\text { groups }\end{array}$ & $\begin{array}{l}\text { Paired } \\
\text { score } \\
\text { changes } \\
\text { within } \\
\text { intervention }\end{array}$ & $\begin{array}{l}\text { Paired } \\
\text { score } \\
\text { changes } \\
\text { within } \\
\text { control }\end{array}$ & Post-Pre & & $\begin{array}{l}\text { Post-Pre } \\
\text { score } \\
\text { changes } \\
\text { between } \\
\text { groups }\end{array}$ \\
\hline & Intervention & Control & ${ }^{a} p$-value & Intervention & Control & ${ }^{a}$ p-value & ${ }^{b} p$-value & ${ }^{b} p$-value & Intervention & Control & ap-value \\
\hline $\begin{array}{l}\text { El } \\
\text { Total }\end{array}$ & $\begin{array}{l}75.0(62.0- \\
81.5)\end{array}$ & $\begin{array}{l}82.0 \\
(77.0- \\
90.0)\end{array}$ & 0.027 & $\begin{array}{l}86.0(80.0- \\
99.0)\end{array}$ & $\begin{array}{l}85.0 \\
(80.0- \\
92.5)\end{array}$ & 0.605 & 0.001 & 0.012 & $\begin{array}{l}13.0(8.0- \\
26.5)\end{array}$ & $\begin{array}{l}4.0 \\
(0.0- \\
8.0)\end{array}$ & 0.002 \\
\hline SEA & $\begin{array}{l}19.0(17.5- \\
21.5)\end{array}$ & $\begin{array}{l}23.0 \\
(20.5- \\
24.0)\end{array}$ & 0.005 & $\begin{array}{l}24.0(22.0- \\
26.0)\end{array}$ & $\begin{array}{l}23.0 \\
(21.0- \\
24.5)\end{array}$ & 0.259 & 0.002 & 0.586 & $\begin{array}{l}5.0(1.0- \\
7.0)\end{array}$ & $\begin{array}{l}0.0 \\
(0.0- \\
1.0)\end{array}$ & 0.001 \\
\hline OEA & $\begin{array}{l}18.0(13.0- \\
20.0)\end{array}$ & $\begin{array}{l}20.0 \\
(17.5- \\
23.5)\end{array}$ & 0.049 & $\begin{array}{l}23.0(19.0- \\
24.0)\end{array}$ & $\begin{array}{l}21.0 \\
(18.5- \\
24.0)\end{array}$ & 0.702 & 0.004 & 0.057 & $\begin{array}{l}6.0(0.5- \\
8.0)\end{array}$ & $\begin{array}{l}0.0 \\
(0.0- \\
2.5)\end{array}$ & 0.027 \\
\hline UOE & $\begin{array}{l}20.0(15.5- \\
22.0)\end{array}$ & $\begin{array}{l}20.0 \\
(17.5- \\
23.0)\end{array}$ & 0.578 & $\begin{array}{l}22.0(20.0- \\
25.0)\end{array}$ & $\begin{array}{l}21.0 \\
(19.0- \\
22.5)\end{array}$ & 0.219 & 0.002 & 0.116 & $\begin{array}{l}3.0(1.0- \\
5.0)\end{array}$ & $\begin{array}{l}0.0 \\
(0.0- \\
2.5)\end{array}$ & 0.017 \\
\hline ROE & $\begin{array}{l}17.0(15.0- \\
21.0)\end{array}$ & $\begin{array}{l}19.0 \\
(18.0- \\
22.0)\end{array}$ & 0.107 & $\begin{array}{l}21.0(18.0- \\
23.5)\end{array}$ & $\begin{array}{l}21.0 \\
(19.5- \\
24.0)\end{array}$ & 0.466 & 0.004 & 0.010 & $\begin{array}{l}3.0(0.0- \\
8.0)\end{array}$ & $\begin{array}{l}2.0 \\
(0.0- \\
3.0)\end{array}$ & 0.252 \\
\hline \multicolumn{12}{|c|}{${ }^{a}$ Mann-Whitney Test for differences between groups } \\
\hline
\end{tabular}

At the 1-month follow-up, El Total and domains scores in the training group remained statistically significantly higher than at baseline (Table 4), confirming that increases in El scores were sustained a month later.

Table 4

Intervention group El scores at 1-month follow-up (FU) and changes from baseline

\begin{tabular}{|llll|}
\hline & 1-month FU & 1-month FU - Baseline & b p-value \\
\hline El Total & $89.0(77.0-95.5)$ & $16.0(10.5-25.5)$ & 0.007 \\
\hline SEA & $23.0(21.0-24.5)$ & $5.0(1.0-6.5)$ & 0.011 \\
\hline OEA & $21.0(19.5-24.5)$ & $4.0(1.0-9.0)$ & 0.010 \\
\hline UOE & $23.0(18.5-26.0)$ & $3.0(1.5-7.0)$ & 0.030 \\
\hline ROE & $20.0(17.0-24.5)$ & $4.0(-0.5-7.0)$ & 0.046 \\
\hline bWilcoxon Signed Ranks Test for paired differences within group \\
\hline
\end{tabular}

\section{Discussion}

This study sought to investigate whether cultivation of El and TA educational training in a group of health professions students can afford students the opportunity to realise improved El and TA capacities immediately after training and at the 1-month follow-up. The findings suggest that exposure to the four weekly 90-minute training sessions resulted in an increase in El outcomes immediately after educational training with a persisting effect one month later.

The concept of El has generated interest in terms of its relevance to well-being regulation, academic performance and occupational effectiveness. More recently evidence is emerging to support the proposition that El can be enhanced through psycho-educational training. El and TA have often formed the theoretical basis for understanding inter-personal dynamics in communication $(25,31,32)$ and leadership $(6,19,33,34)$ skills. Training based on both theoretical underpinnings have been reported to result in positive outcomes $(12,23)$. The present study introduced a sample of undergraduates to the concepts of El and TA on a weekly basis for four weeks, at 90 minutes each time, and provided opportunities to apply the concepts of TA and El to social encounters experienced in the previous week. Students also explored the emotions that they felt during these encounters and discussed mechanisms used to cope with those emotions. The experiential sharing part of the training offered the opportunity to understand the structure and functioning of their individual personality and recognize how they respond to others. By listening and watching how others share their experiences, group members learned to identify their own emotions better. This training programme took advantage of the 
synergistic learning experience of both concepts (16) and the result was a sustained increase in El among students who took part in the training. Previous research has similarly reported the effectiveness of TA training in enhancing El and empathy. In one study exposing 16 nurses to a psychoeducational training on TA, Whitley-Hunter (16) positive impact on participants communication skills and empathy scores. In another study, 15 subjects participated in 12 sessions of A-based group psychotherapy, and were shown to have increased El compared to subjects who were not exposed to the intervention (18). Results from the present study suggest that increases in El scores in the training group were higher than in the control group in the SEA, OEA and UOE domains. In identifying the ego states manifested in an interpersonal transaction and any possible conflicts that may emerge, an individual can begin to appraise the emotions that are aroused in themselves and others. That individual can then decide on the next course of action based on the emotions they feel. However, no difference in improvement in the ROE domain was detected between the training and control groups. It is possible that development of the ROE skill may require a longer period of training and practice than that afforded by the present training programme. Further research is needed to explore training that can promote emotional regulation.

In the present study, more female students volunteered for the TEITA than male students. At baseline male subjects scored more highly in El than female subjects. However, on completion of TEITA, El scores in the females increased substantially such that differences with males lost statistical significance, and there were no differences in El scores changes between females and males. Since females were over-represented in the TEITA group, increases in El scores were likely to be due to the training. This highlights a limitation of the present study, in that it was not able to show whether the training was able effect El improvement in male subjects, although it has been reported that females are more likely to benefit from El training (13).

The risk of self-selection bias in non-randomised studies can lead to biased estimates in terms of balance of motivation in investing and completing the training. However, this lack of balance has only a small impact on the outcome because, the El scores of the TEITA subjects at baseline were lower than the control subjects, and significant increases in El scores were clearly detected post-training. Furthermore, improvement in El scores were sustained at the 1-month follow-up.

\section{Conclusion}

In conclusion, within some limitations, a psycho-educational training based on El and TA has been shown to be effective in enhancing El in health professions students. Future research is needed to test this intervention in different populations. Research should also investigate the effect of such TA and El training on observable inter-personal and socio-economic behaviours.

\section{Abbreviations}

El- Emotional Intelligence

TA- Transactional analysis

TEITA- Training in emotional intelligence and transactional analysis

WLEIS- Wong and Law Emotional Intelligence Scale

SEA- Self-emotional appraisal

OEA- Others' emotional appraisal

UOE- Use of emotion

ROE- Regulation of emotion

\section{Declarations}

- Ethics approval and consent to participate

The study protocol was carried out in accordance with the Declaration of Helsinki.The study was approved by the IMU Institutional ethics committee (BDS I1-13(13)-2016) and informed consent was obtained from all subjects who participated in the study.

- Consent for publication

Not applicable

- Availability of data and materials

All data generated or analyzed during this study are included in this published article

- Competing interests 
The authors declare that they have no competing interests.

- Funding

The research was funded by the university as part of short study module project under grant number ID IJ185.

- Authors' contributions

$\mathrm{PKH}$ and MM were responsible for the conception of the study design. PKH was a major contributor in writing the manuscript. SHY and WHL were responsible for data collection and interpretation. $\mathrm{MNH}$ and $\mathrm{KHE}$ designed and conducted the intervention as well as contributed to the initial study proposal. All authors read and approved the final manuscript

- Acknowledgements

The authors acknowledge and appreciate the contributions of volunteer students.

\section{References}

1. Mayer JD, Salovey P, Caruso DR. Emotional Intelligence: New Ability or Eclectic Traits? Am Psychol. 2008;63(6):503-17.

2. Ranasinghe P, Wathurapatha WS, Mathangasinghe $Y$, Ponnamperuma G. Emotional intelligence, perceived stress and academic performance of Sri Lankan medical undergraduates. BMC Med Educ. 2017;17(1).

3. Singh N, Kulkarni S, Gupta R. Is emotional intelligence related to objective parameters of academic performance in medical, dental, and nursing students: A systematic review. Vol. 33, Education for Health: Change in Learning and Practice. 2020. p. 8-12.

4. Arora S, Ashrafian H, Davis R, Athanasiou T, Darzi A, Sevdalis N. Emotional intelligence in medicine: A systematic review through the context of the ACGME competencies. Vol. 44, Medical Education. 2010. p. 749-64.

5. Dugan JW, Weatherly RA, Girod DA, Barber CE, Tsue TT. A longitudinal study of emotional intelligence training for otolaryngology residents and faculty. JAMA Otolaryngol - Head Neck Surg. 2014;140(8):720-6.

6. Mintz LJ, Stoller JK. A Systematic Review of Physician Leadership and Emotional Intelligence. J Grad Med Educ. 2014;6(1):21-31.

7. Guerrero-Barona E, Guerrero-Molina M, García-Gómez A, Moreno-Manso JM, García-Baamonde ME. Quality of working life, psychosocial factors, burnout syndrome and emotional intelligence. Int J Environ Res Public Health. 2020;17(24):1-15.

8. Soto-Rubio A, Giménez-Espert MDC, Prado-Gascó V. Effect of emotional intelligence and psychosocial risks on burnout, job satisfaction, and nurses' health during the covid-19 pandemic. Int J Environ Res Public Health. 2020;17(21):1-14.

9. Akerjordet K, Severinsson E. Emotional intelligence: A review of the literature with specific focus on empirical and epistemological perspectives. J Clin Nurs. 2007;16(8):1405-16.

10. Johnson DR. Emotional intelligence as a crucial component to medical education. Vol. 6, International journal of medical education. 2015. p. 179-83.

11. Taylor C, Farver C, Stoller JK. Perspective: Can emotional intelligence training serve as an alternative approach to teaching professionalism to residents? Vol. 86, Academic Medicine. 2011. p. 1551-4.

12. Cherry MG, Fletcher I, O'Sullivan H, Dornan T. Emotional intelligence in medical education: A critical review. Med Educ. 2014;48(5):468-78.

13. Cherry MG, Fletcher I, O'Sullivan $\mathrm{H}$, Shaw N. What impact do structured educational sessions to increase emotional intelligence have on medical students? BEME Guide No. 17. Med Teach. 2012;34(1):11-9.

14. Abe K, Evans P, Austin EJ, Suzuki Y, Fujisaki K, Niwa M, et al. Expressing one's feelings and listening to others increases emotional intelligence: $A$ pilot study of Asian medical students. BMC Med Educ. 2013;13(1).

15. Kelly D, McErlean S, Naff K. Outcomes of a clinical leadership training program amongst hospital doctors. Ir Med J. 2018;111(4):733.

16. Whitley-Hunter BL. Validity of transactional analysis and emotional intelligence in training nursing students. J Adv Med Educ Prof [Internet]. 2014;2(4):138-45. Available from: http://www.ncbi.nlm.nih.gov/pubmed/25512937\%0Ahttp://www.pubmedcentral.nih.gov/articlerender.fcgi? artid=PMC4235560

17. Thiagarajan P, McKimm J. Mapping transactional analysis to clinical leadership models. Vol. 80, British Journal of Hospital Medicine. 2019. p. 600-4.

18. Forghani M, Ghanbari Hashem Abadi BA. The effect of group therapy with transactional analysis approach on emotional intelligence, executive functions and drug dependency. Iran J Psychiatry Behav Sci. 2016;10(2).

19. McKimm J, Forrest K. Using transactional analysis to improve clinical and educational supervision: The Drama and Winner's triangles. Vol. 86, Postgraduate Medical Journal. 2010. p. 261-5.

20. Sablik Z, Samborska-Sablik A, Drozdz J. Universality of physicians' burnout syndrome as a result of experiencing difficulty in relationship with patients. Arch Med Sci. 2013;9(3):398-403.

21. Nitschke I, Müller F, Hopfenmüller W. The uptake of dental services by elderly Germans. Gerodontology. 2001;18(2):114-20.

Page $7 / 8$ 
22. Sivan M, McKimm J. Can an understanding of transactional analysis improve postgraduate clinical supervision? Br J Hosp Med. 2011;72(1):448.

23. Rajan M, Chacko T. Improving educational environment in medical colleges through transactional analysis practice of teachers. F1000Research. 2012;1.

24. Hur Y, Cho A-R. The relationship between ego-state and communication skills in medical students. Korean J Med Educ. 2014;26(1):59-62.

25. Lawrence L. Applying transactional analysis and personality assessment to improve patient counseling and communication skills. Am J Pharm Educ. 2007;71(4).

26. Sheldon LK, Ellington L. Application of a model of social information processing to nursing theory: How nurses respond to patients. J Adv Nurs. 2008;64(4):388-98.

27. Wong CS, Law KS. The effects of leader and follower emotional intelligence on performance and attitude: An exploratory study. Leadersh Q. 2002;13(3):243-74.

28. Fukuda E, Saklofske DH, Tamaoka K, Lim H. Factor Structure of the Korean Version of Wong and Law's Emotional Intelligence Scale. Assessment. 2012;19(1):3-7.

29. Iliceto P, Fino E. The Italian version of the Wong-Law Emotional Intelligence Scale (WLEIS-I): A second-order factor analysis. Pers Individ Dif. 2017;116:274-80.

30. Law KS, Wong CS, Song LJ. The construct and criterion validity of emotional intelligence and its potential utility for management studies. Vol. 89, Journal of Applied Psychology. 2004. p. 483-96.

31. Keçeci A, Taşocak G. Nurse faculty members' ego states: Transactional Analysis Approach. Nurse Educ Today. 2009;29(7):746-52.

32. Partido BB, Stefanik D. Impact of emotional intelligence training in a communication and ethics course among second-year dental students. J Dent Educ. 2020;84(6):704-11.

33. Reed BN, Klutts AM, Mattingly TJ. A systematic review of leadership definitions, competencies, and assessment methods in pharmacy education. Vol. 83, American Journal of Pharmaceutical Education. 2019. p. 1873-85.

34. True MW, Folaron I, Colburn JA, Wardian JL, Hawley-Molloy JS, Hartzell JD. Leadership Training in Graduate Medical Education: Time for a Requirement? Mil Med. 2020;185(1-2):E11-6.

\section{Figures}

\begin{tabular}{|c|c|c|c|}
\hline Session 1 & $\begin{array}{l}6.00-6.15 \mathrm{pm} \\
6.15-6.30 \mathrm{pm} \\
6.30-6.40 \mathrm{pm} \\
6.40-7.30 \mathrm{pm} \\
7.30 \mathrm{pm}\end{array}$ & $\begin{array}{l}\text { Explanation of ground rules } \\
\text { PowerPoint presentation on EI } \\
\text { Ice breaking game } \\
\text { Experiential sharing } \\
\text { Wrap up and summary }\end{array}$ & $\begin{array}{l}\text { SHY and WHL } \\
\text { SHY } \\
\text { KHE and MNH } \\
\text { KHE and MNH } \\
\text { SHY and WHL }\end{array}$ \\
\hline Session 2 & $\begin{array}{l}6.00-6.25 \mathrm{pm} \\
6.25-6.40 \mathrm{pm} \\
6.40-7.30 \mathrm{pm} \\
7.30 \mathrm{pm}\end{array}$ & $\begin{array}{l}\text { Review on previous session } \\
\text { PowerPoint presentation on TA } \\
\text { Experiential sharing } \\
\text { Wrap up and summary }\end{array}$ & $\begin{array}{l}\text { SHY and WHL } \\
\text { WHL } \\
\text { KHE and MNH } \\
\text { SHY and WHL }\end{array}$ \\
\hline Session 3 & $\begin{array}{l}6.00-6.40 \mathrm{pm} \\
6.40-7.30 \mathrm{pm} \\
7.30 \mathrm{pm}\end{array}$ & $\begin{array}{l}\text { Ego states determination by using } \\
\text { TA Questionnaire } \\
\text { Experiential sharing } \\
\text { Wrap up and summary }\end{array}$ & $\begin{array}{l}\text { KHE and MNH } \\
\text { KHE and MNH } \\
\text { SHY and WHL }\end{array}$ \\
\hline Session 4 & $\begin{array}{l}6.00-7.00 \mathrm{pm} \\
7.00-7.15 \mathrm{pm} \\
7.15-7.30 \mathrm{pm}\end{array}$ & $\begin{array}{l}\text { Experiential sharing } \\
\text { Post intervention questionnaire } \\
\text { Wrap up and summary }\end{array}$ & $\begin{array}{l}\text { KHE and MNH } \\
\text { SHY and WHL } \\
\text { SHY and WHL }\end{array}$ \\
\hline
\end{tabular}

\section{Figure 1}

Schedule of TEITA Delivery 